\title{
Synthesis, characterization and evaluation of in vitro antioxidant and anti-inflammatory activity of 2-(4-oxo-2-phenylquinazolin-3(4H)-yl) substituted acetic acids
}

\author{
B.Haseena Banu ${ }^{1 *}$, K. Bharathi $^{2}$ and KVSRG Prasad ${ }^{3}$ \\ 1,2,3 (Department of Pharmaceutical Chemistry, Institute of Pharmaceutical Technology, \\ Sri Padmavathi Mahila Visvavidyalayam(Women's University),Tirupati,A.P,India.
}

\begin{abstract}
Quinazolinone nucleus is a very attractive and useful scaffold in medicinal chemistry. It had been a pharmacophore in a wide variety of biologically active compounds. Peptides are key regulators in cellular and intercellular physiological responses and possess enormous promise for the treatment of pathological conditions. Prompted by therapeutic importance of quinazolinones and peptide derivatives, these two vital moieties were combined together into a single molecule by varying the different amino acids were synthesized, characterized and evaluated for anti-inflammatory and antimicrobial activities.
\end{abstract}

Keywords: - Amino acids, antioxidant, anti-inflammatory, benzoxizanone, peptides,quinazolinone

\section{Introduction}

Heterocyclic chemistry comprises at least half of all organic chemistry research worldwide. In particular, heterocyclic structures form the basis of many pharmaceutical, agrochemical and veterinary products. Among a wide variety of nitrogen heterocycles that have been explored for developing pharmaceutically, quinazolinone plays an important role in medicinal chemistry and subsequently have emerged as a pharmacophore. Quinazolinones are classes of fused heterocycles that are of considerable interest because of the diverse range of their biological activities such as farnesyltransferase, gastric $\mathrm{H}+/ \mathrm{K}+-$ ATPase and MAP kinase p38 inhibitory properties [1], anticancer[2-5], antiulcer[6], anti-tubercular[7], anti-bacterial and antifungal[8-11], anti-HIV[12],CNS depressant[13] , anticonvulsant[14], antihelmintic[15], analgesic and antiinflammatory[16-18], antihypertensive[19], antidiabetic[20] and anti-oxidant activities[21].

Peptides are active regulators and information breakers and possess enormous promise for the treatment of pathological conditions that make them interesting for drug discovery. Opioid peptide activity within the central nervous system (CNS) is of particular interest for the treatment of pain owing to the elevated potency of peptides and the centrally mediated actions of pain processes. They are the molecules of paramount importance in the fields of health care and nutrition controlling the numerous body processes and represent as promising drugs of the future [22]. Despite their potential, peptides have been of limited use as clinically viable drugs chiefly due to their undesired intrinsic properties. Therefore the challenge of this decade is to produce small molecules which mimic peptides and proteins. Incorporation of peptides into the aromatic and heterocyclic congeners results in compounds with potent bioactivities. Thus, keeping in mind the pharmacological potential of quinazolinones and peptides as well as taking advantage of biodegradability and biocompatibility of peptides, peptide derivatives of quinazolinone were prepared to increase therapeutic efficacy.(introduction of research article)Quinazolinone peptides were reported for their anti-inflammatory,antioxidant,anthelminthic,antibacterial and antifungal activities[23,24]. In view of their therapeutic importance, quinazolinone peptide derivatives were synthesized,characterized and evalauated for in vitro antioxidant and anti-inflammatory activities.

\section{Materials and methods}

Melting points were determined in an open capillary tube in Sigma Melting point apparatus and are uncorrected. Infrared Spectra of compounds were measured on a PE FTIR, in KBr disc and absorption bands expressed in $\mathrm{cm}^{-1}$. 1HNMR Spectra were recorded on a Bruker Avance dpx-200(at $200 \mathrm{MHZ}$ )Spectrometer with $\mathrm{CDCl}_{3}$ as a solvent with tetramethylsilane(TMS) as an internal reference. Mass spectra were scanned on Jeol GCmate Mass spectrophotometer. Thin layer chromatography was carried out on silica gel to monitor the reactions and to check the purity of the compounds. All reagents were of the highest purity available commercially.Arginine, Histidine,Leucine,Glycine,Alanine,Aspargine, Glutamine, acetone, sodium hydroxide,N-benzoyl glycine, anthranilic acid and ethanol are procured from E.MERCK Ltd,Mumbai.Methionine and proline obtained from SISCO research laboratories PVT Ltd, Mumbai. The Eddys Hot plate instrument is from Sigma,Chennai. 


\subsection{Chemistry}

2.1.1 Synthesis of 2-phenyl-4H-benzo[d][1,3]oxazin-4-one:To a stirred solution of anthranilic acid $(0.05 \mathrm{~mol})$ in pyridine $(60 \mathrm{ml})$, benzoyl chloride $(0.05 \mathrm{~mol})$ was added drop wise, maintaining the temperature $0-5^{0} \mathrm{C}$ for $1 \mathrm{hr}$. The reaction mixture was stirred for another $2 \mathrm{hrs}$ at room temperature until the solid product was formed. The reaction mixture was neutralized with saturated sodium bicarbonate solution and pale yellow solid which separated was filtered, washed with water, and recrystallized from ethanol. Yield-85\%, M.P- $113-115^{\circ} \mathrm{C}$ (Lit.113-115 $\mathrm{C}$ )

2.1.2General Method of Synthesis of 2-(4-oxo-2-phenylquinazolin-3(4H)-yl)substituted acetic acids (B1-B15) : Glycine $(0.01 \mathrm{~mol})$ in glacial acetic acid $(10 \mathrm{ml})$ and dry pyridine $(10 \mathrm{ml})$ was added to 2-phenyl-benzoxazine-4-one $(0.01 \mathrm{~mol})$ and refluxed for $4 \mathrm{hrs}$. The obtained reaction mixture was poured in to crushed ice and left overnight. The solid was filtered, washed with cold water, and re-crystallized from ethanol to obtain 2-(4-oxo-2-phenylquinazolin-3(4H)-yl) acetic acid (B1). Compounds B2-B15 were synthesized by the above mentioned procedure by condensing 2-phenyl-4H-benzo[d][1,3]oxazin4-one with different amino acids. The scheme for synthesis is represented in Fig.1

\subsection{Pharmacological activities}

\subsubsection{In vitro antioxidant activity}

2.2.1.1. Interaction with stable free radical DPPH: Stable free radical species such as 1, 1-diphenyl-2-picrylhydrazyl (DPPH) is often used for the evaluation of the general radical scavenging capabilities of various antioxidants. DPPH, a paramagnetic compound with an odd electron, shows strong absorption band at $517 \mathrm{~nm}$. The absorbance decreases as a result of colour change from purple to yellow due to the scavenging of free radical by anti-oxidants through donation of hydrogen to form the stable DPPH-H molecule.

Solutions of various drugs at $100 \mu \mathrm{M}$ concentration were added to $100 \mu \mathrm{M}$ DPPH in $95 \%$ ethanol and tubes were kept at an ambient temperature for 20 minutes and absorbance was measured at $517 \mathrm{~nm}$. The drug concentration having $50 \%$ radical inhibition activity $\left(\mathrm{IC}_{50}\right)$ was calculated from the graph of $\%$ of free radical scavenging activity against the drug concentration. (Note: DPPH solution should be made freshly and should be kept in dark.)[25,26] .

$$
\text { Inhibition }(\%)=\frac{(\text { Control }- \text { Test })}{\text { Control }} \times 100
$$

2.2.1.2Scavenging of nitric oxide radical : Nitric oxide was generated from sodium nitroprusside and measured by Griess' reaction . Sodium nitroprusside $(5 \mathrm{mM})$ in standard phosphate buffer $\mathrm{pH} 7.4$ were incubated with $100 \mu \mathrm{M}$ concentrations of drug dissolved in a suitable solvent (dioxan/methanol) and the tubes were incubated at $25^{\circ} \mathrm{C}$ for 5 hrs. Control experiment was conducted in an identical manner without test compound but with equal amount of solvent. After $5 \mathrm{hrs}$, $0.5 \mathrm{ml}$ of incubation solution was removed and diluted with $0.5 \mathrm{ml}$ of Griess' reagent . The absorbance of the chromophore formed during diazotization of nitrite with sulphanilamide and its subsequent coupling with N-napthyl ethylene diamine was read at 546nm . Composition of Griess reagent is Sulphanilamide $(1 \%)+\mathrm{N}-$ Napthylethylene diamine $(0.1 \%)+$ Orthophosphoric acid( $2 \%)$ in 100ml Distilled water [27,28].

$$
\text { Inhibition }(\%)=\frac{(\text { Control }- \text { Test })}{\text { Control }} \times 100
$$

2.2.2. Acute inflammatory model-carrageenan induced paw edema assay: Male and female albino rats (150-200g) were used. The animals were fed with commercial feed pellets and were given water ad libitum.Carrageenan was obtained from s d fine chem. Ltd .Paw edema was measured by UGO BASILE 7140 Plethysmometer.

The rats were divided into 15 groups, one group consisting of six animals served as control, while the other groups of five animals each received the test compounds and standard drug. The rats were administered orally with test compounds (100 $\mathrm{mg} / \mathrm{kg}$ ), $100 \mathrm{mg} / \mathrm{kg}$ Diclofenac sodium or Ibuprofen (positive controls) or $10 \mathrm{ml} / \mathrm{kg} 0.5 \%$ sodium carboxy methyl cellulose (vehicle controls) one hour before injection of $0.05 \mathrm{ml}$ of $1 \%$ suspension of Carrageenan into the sub plantar region of the rat hind paw.

The volume of the injected paw was measured by water displacement in a digital plethysmograph immediately after carrageenan injection. The paw volume was again measured after 3 hours. A mark was made at the lateral maleolous of the right paw and the foot was dipped to the same distance of the mark into the arm of plethysmograph. Average edema volumes 
for test compound treated and positive control rats were compared statistically with those of the vehicle control animals and expressed as percent edema inhibition, which is calculated using the formula. (Otterness I et al., 1985).

Percentage edema inhibition $=100(1-\mathrm{Vt} / \mathrm{Vc})$

Where, $\mathrm{Vt}=$ volume of edema in treated group, $\mathrm{Vc}=$ volume of the edema in the control group

Statistical analysis: Statistical analysis of the differences observed between control and treated groups were carried out using ANOVA. P value $<0.05$ was considered significant. Dunnett's post ANOVA has been done.

\section{Results and Discussion}

3.1. Chemistry

Fifteen compounds (B1-B15) were synthesized with the yields generally ranging from 70-90\%. (B8) and (B9) derivatives were obtained at lowest yield $45-50 \%$. The physical data such as melting points and yields are given in the Table I. The quinazolinone derivatives of the present study were characterized by UV, IR, ${ }^{1} \mathrm{H}$ NMR, and mass spectral analysis. The UV absorption peaks were observed in the region of the230-320nm.

The IR spectra of all compounds displayed characteristic bands IR (KBr): $v 3365(\mathrm{O}-\mathrm{Hstr}, \mathrm{Ar}-\mathrm{OH}), 3295-2505$ (O-Hstr,COOH), 3072-3066, 3052 (Ar-Hstr), 2967, 2875 (C-Hstr, CH3), 1702 (C=Ostr, COOH), 1669 (C=Ostr, ring), 1589, 1575, 1425, 1417 (skeletal bands), 1405 (O-Hdef, $\mathrm{COOH}), 875,836,760,752,696$ (C-Hdef, Ar), strong bands at $\mathrm{cm}^{-1}$ due to $\mathrm{C}=\mathrm{O}$ (in ring) stretching, $\mathrm{cm}^{-1} 3000-3085$ due to $\mathrm{C}-\mathrm{H}(\mathrm{Ar}-\mathrm{H})$ stretching, $\mathrm{cm}^{-1} 1400-1587$ due to $\mathrm{C}=\mathrm{C}$ stretching (Ar).

${ }^{1} \mathrm{H}$ NMR spectra were taken for all the compounds which also supported the structures assigned. All the compounds displayed multiplets in the region of $\delta$ 6.6-8.3 due to aromatic hydrogen $(\mathrm{Ar}-\mathrm{H})$ in additional Compound B2 displayed a doublet in the region of $\delta 1.15-1.22$ due to $-\mathrm{CH}_{3}$ protons and quartet in the region of $\delta$ 4.3-4.5 due to $-\mathrm{CH}-$ proton and a singlet in the region of $\delta 11.3-11.5$ due to $\mathrm{COO}$,. Compound B4 displayed a doublet in the region of $\delta 1.2-1.3$ due to $\mathrm{SH}$, a triplet at 2.5-2.8 due to $-\mathrm{CH}_{2}$ protons another triplet in the region of 4-4.3 due to $-\mathrm{CH}$ proton Compound B8 displayed a doublet in the region of $\delta$ 2.7-2.9 due to $\mathrm{O}-\mathrm{H}$ proton $(\mathrm{CH}-\mathrm{OH})$. The structure of the compounds was also assigned by mass spectral analysis which showed $(\mathrm{M}+)$ peaks of the compounds.

\subsection{In vitro antioxidant activity}

3.2.1.Reduction of DPPH:All the compounds (B1-B15)were screened for reduction of DPPH.The highest activity of 84.9\% was exhibited by B15, with guanidine group moiety.The compound with simplest amio acid ,glycine (B1) showed only $35.6 \%$ of activity. When the alkyl chain was increased, there was no change in activityB2,B3,B4 exhibited 37.8,39.6 and $42.2 \%$ of activities respectively. When polar side chain amino acids were introduced, such as hydroxyl containing serine, threonine and tyrosine and sulfhydryl containing cysteine there was an increase in activity observed. B5,B7,B8,B11 exhibited 79,78.1,76.2 \&82.4\% activities respectively. The results are given in Table-II

3.2.2. Nitric oxide radical scavenging: All the compounds(B1-B15) were tested for the scavenging of the nitric oxide free radical .Interestingly the compounds exhibited the same pattern of activity as in case of DPPH reduction. The compound with simplest amio acid ,glycine (B1) showed only $31.2 \%$ of activity. When the alkyl chain was increased, there was no change in activityB2,B3,B4 exhibited 33.1,32.9 and 38.5\% of activities respectively. When polar side chain amino acids were introduced, such as hydroxyl containing serine, threonine and tyrosine and sulfhydryl containing cysteine there was an increase in activity observed. B5, B7, B8, B11 exhibited 68.2, 61.6, $72.3 \& 79.1 \%$ activities respectively. The highest activity of $79.7 \%$ was exhibited by B15, with guanidine group moiety. The results are given in Table-II

\subsection{Anti-iflammatory activity}

Among the tested compounds, the compound B1 exhibited $45.2 \%$ edema inhibition, when the compounds were prepared using non polar aliphatic and aromatic amino acids there was no much difference in the activity(43-50\%). The compounds with polar aliphatic and polar aromatic amino acids there was a considerable rise in potency (57-69.8\%). The compound B16 with arginine exhibited the highest anti-inflammatory activity of $71.6 \%$. 


\section{Conclusion}

The synthetic procedure was easier and \%yields of the compounds were fairly good(78-92\%). All the compounds exhibited moderate to potent and significant antioxidant and anti-inflammatory activities. Compound B15 showed extreme significant activity. The presence of essential structural features of good antioxidants in the synthesized compounds satisfy the criteria and thus proved to be potent. The ongoing development of these strategies provides promise that quinazolinone peptide drugs may be useful for the treatment of variety of diseases related to free radicals and inflammation.

Acknowledgement: We are thankful to IPT,SPMVV,Tirupati for providing the necessary facilities ,IIT madras for spectral data and UGC-New Delhi for granting the RFSMS.

\section{References}

[1] P.Angibau,X.Bourdrez,A.Devine,D.W.End,E.Freyne,Y.Lignye et al, W. 5-Imidazolyl-quinazolinones, -benzoazepinones as farnesyltransferase inhibitors, Bioorg. Med. Chem. Lett. , 13,2003, 1543-1547.

[2] Sheng-Li cao, Yu-Ping Feng, Yu-Yang Jiang, Shi-Ying Liu, Guo-Yu Ding and Run-Tao Li; Synthesis and in vitro antitumour activity of $4(3 \mathrm{H})$-quinazolinone derivatives with dithiocarbamate side chains. Bioorganic and medicinal chemistry letters, 15(7),1 2005, 1915-1917.

[3] Yuvaraj Govindaraj, Sathyamoorthy, Venkatesh Karthikeyan, Vijyalakshmi Melanaphuru, Vivek Agrahari, Sandeep Gupta and Rajesh Kumar Nema, Synthesis and In-vivo Anticancer Screening of 2-\{[Bis-(2Chloroethyl) Amino] Methyl $\}$ - 6, 8-Dinitro-1- (4-Substituted Ethyl)-1h-quinazolin-4-One Derivatives. Academic Journal of Cancer Research ,2 (2),2009, 73-77.

[4] D.Raffa,M.C.Elder,G.Daidone, B.Maggio,M. Merickech, S.Plescia, D.Schillaci, R.Bai and E.Hamel,Synthesis, cytotoxity and inhibitory effects on tubulin polymerization of a new 3-heterocyclo substituted 2styrylquinazolinones. Eur. J. Med. Chem. , 39,2004, 299-304.

[5] N.Ho,R.S. Harapanhalli,B.A. Dahman,K.Chen, K. Wang, S.J. Adelstein and A.I. Kassis,Synthesis and biologic evaluation of a radioiodinated quinazolinone derivative for enzymemediated insolubilization therapy. Bioconjug. Chem. 13,2002,, 357-364.

[6] Avinash Patil1, Swastika Ganguly and Sanjay Surana ,Synthesis and antiulcer activity of 2-[5-substituted-1-Hbenzo (d) imidazol-2-yl sulfinyl] methyl-3-substituted quinazoline-4-(3H) ones. J. Chem. Sci., 122( 3), 2010, $443-450$.

[7] S.R.Pattan,VVK. Reddy,F.V. Manvi,B.G. Desai and A.R. Bhat, Synthesis of N-3-(4-(4- chlorophenyl-thiazol-2yl)-(2-(amino)methyl)-quinazoline-4(3H)-one and their derivatives for antitubercular activity. Indian J. Chem,45B 2006, 1778-1781.

[8] Vivek Gupta, Sushil K. Kashaw ,Varsha Jatav, Pradeep Mishra ,Synthesis and antimicrobial activity of some new 3-[5-(4-substituted) phenyl-1,3,4-oxadiazole-2yl]-2- styrylquinazoline-4(3H)-ones. Med Chem Res,17, $2008,205-211$.

[9] Chatrasal Singh Rajput, Sanjeev Kumar,Ashok kumar,Synthesis and antifungal activity of newer substituted quinazolinones, International journal of Chemical technology and research,2(3),2010, 1653-1660.

[10] N.C.Desai,P.N. Shihora and D.L. Moradia , Synthesis and characterization of new quinazolines as potential antimicrobial agents. Indian J. Chem. 46B, 2007, 550-553.

[11] A.K.Sengupta and T. Bhattacharya, Synthesis and antimicrobial activity of some substituted 2-phenyl-3arylquinazol-4-ones. J. Indian Chem. Soc, 60, 1983, 373-376.

[12] V.Alagarsamy,R.Giridhar,M.R. Yadav, R. Revathi,K. Ruckmani and E. De Clercq, Anti HIV, antibacterial, and antifungal activities of some novel 1,4-disubstituted-1,2,4-triazolo[4,3-a]quinazolin-5(4H)-ones. Indian J. Pharm. Sci. 2006, 68, 532-535. 
[13] Varsha jatav, Pradeep Mishra, Sushil Kashaw, and J.P.Stables, Synthesis and CNS depressant activity of some novel 3-[5-substituted phenyl-1,3,4-thiadiazole-2-yl]-2-styryl quinazolin-4(3H)-ones, European Journal of Medicinal Chemistry ,43,2008, 135-141.

[14] C.O.Usifoh and K.E.Scriba, Synthesis and anticonvulsant activity of acetylenic quinazolinone derivatives. Arch. Pharm. Pharm. Med. Chem., 333 2000, 261-266.

[15] Rajiv Dahiya, Anil Kumar and Rakesh Yadav ,Synthesis and Biological Activity of Peptide Derivatives of Iodoquinazolinones/Nitroimidazoles, Molecules,13, 2008, 958-976.

[16] T.Panneer Selvam ,C.R. Prakash, G.Saravanan ,V. Karthick and P. Dinesh kumar,Rasayan J.Chem. 2,2009,753.

[17] M.R.Yadav , S. T. Shirude, A. Parmar, R. Balaraman, and R. Giridhar. Synthesis and anti-inflammatory activity of 2, 3-diaryl- 4(3H)-quinazolinones. Chemistry of Heterocyclic Compounds, 42( 8), 2006,1038-1045.

[18] A.Yesilada,S. Koyunoglu,N. Saygili,E. Kupeli, E.Yesilada, E. Bedir and I. Khan, Synthesis,anti-inflammatory and analgesic activity screening of some new 4(3H)-quinazolinone derivatives. Arch. Pharm. Pharm. Med. Chem,337, 2004, 96-104.

[19] Wright W B , Tomcufcik A S, Chan P S, Marsico J W and Press J B, J. Med. Chem,30,1987, 2277

[20] A.Munir Hussain,T. Andrew Chiu, A.William, Price,B. Pieter Timmermans and Eli Shefter, Antihypertensive activity of 2[(2-Hydroxyphenyl)amino]-4(3H)-quinazolinone. Pharmaceutical research, 5(4), 1988,242-244.

[21] Rajveer Ch, D. kumaraswamy, S.Sudharani \& B.Stephen rathinaraj; Synthesis of some 6-bromo quinazolinone derivatives for their pharmacological activities, International Journal Of Pharma And Bio Sciences, 1(3),2010,110 .

[22] Burger's Medicinal Chemistry and Drug Discovery, Fifth Edition: Principles and Practice, Edited by Manfred E.Wolf,Volume1

[23] Amar R. Desai and Kishor R. Desai, Niementowski reaction: microwave induced and conventional synthesis of quinazolinones and 3-methyl-1H-5-pyrazolones and their antimicrobial activity, ARKIVOC (xiii) ,2005, 98108.

[24] Sachin S.Laddha, Satyendra p. Bhatnagar,A new therapeutic approach in Parkinson's disease: some novel quinazoline derivatives as dual selective phosphodiesterase 1 inhibitors and anti-inflammatory agents. Bioorganic \& Medicinal Chemistry Letters, 17, 2009, 6796-6802.

[25] A.Cotelle ,JL Bernier, J PCatteau,J. Pommery ,J C. Wallet and E M Gaydou ,Antioxidant properties of hydroxy-flavones, Free Radic Biol Med, 1996; 20: 35.

[26] A.Shirwaikar ,K. Rajendran and C.Dinesh Kumar , In vitro antioxidant studies of Annona squamosa Linn leaves, Indian J Exp Biol,42, 2004,803.

[27] N.Sreejayan and M N A Rao, Nitric oxide scavenging by curcuminoids, J Pharm Pharmacol,49, 1997, 105.

[28] L.Marcocci, J.Maguire, M T.Droy-Lefaix and L.Packer, The nitric oxide scavenging properties of Ginkgo biloba extract EGB 761, Biochem Biophys Res Commun,201, 1994,748. 
IOSR Journal of Pharmacy

Vol. 2, Issue 1, Jan-Feb.2012, pp. 097-104

Fig.1 : General method for preparation of 2-(4-oxo-2-phenylquinazolin-3(4H)-yl)substituted acetic acids

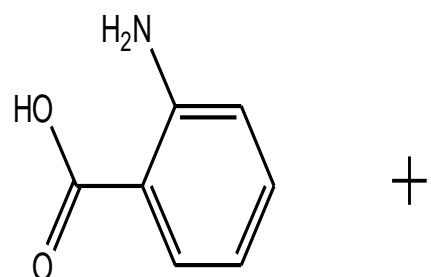

anthranilic acid

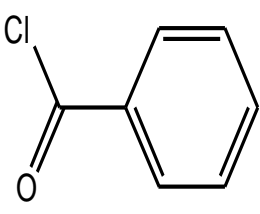

benzoyl chloride

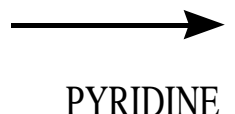

PYRIDINE<smiles>O=c1oc(-c2ccccc2)nc2ccccc12</smiles>

2-phenyl-4H-benzo[d][1,3]oxazin-4-one

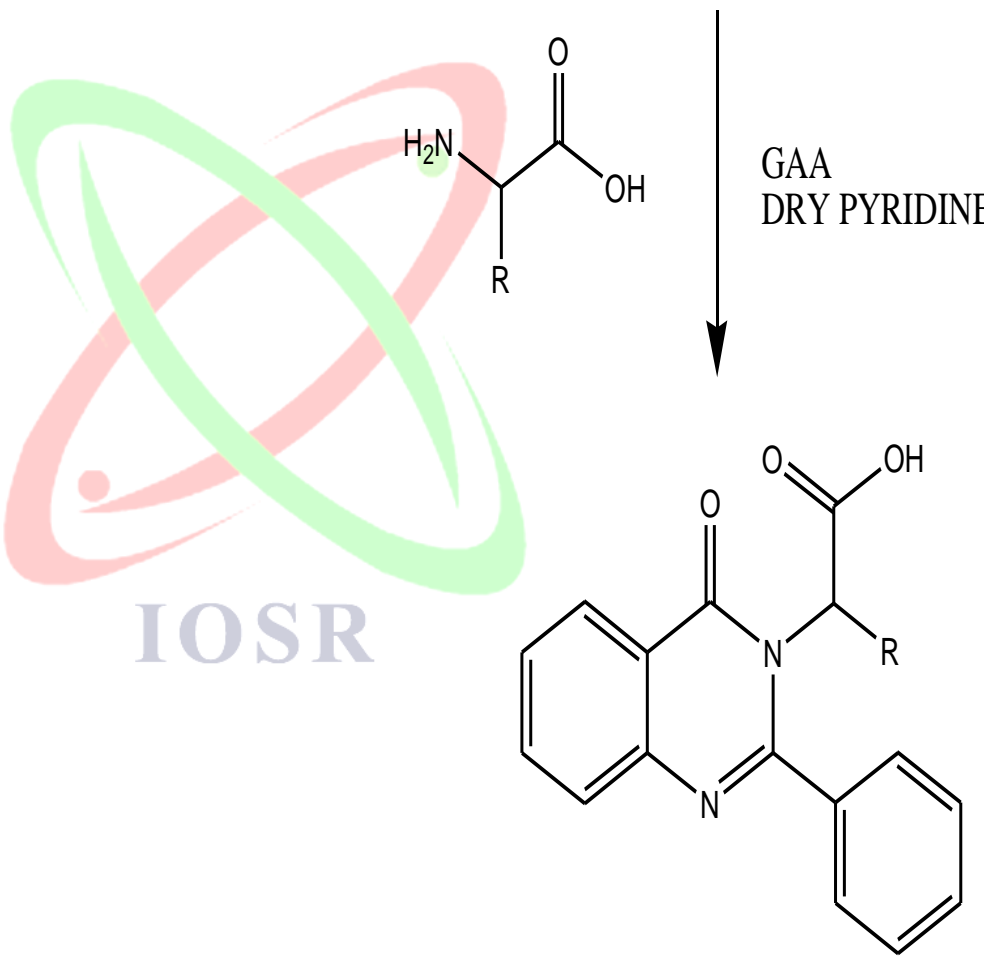

2-(4-0x0-2-phenylquinazolin-3(4H)-yl)acetic acids (B1-B15) 
IOSR Journal of Pharmacy

Vol. 2, Issue 1, Jan-Feb.2012, pp. 097-104

Table I: Physical data of 2-(4-oxo-2-phenylquinazolin-3(4H)-yl)substituted acetic acids (B1-B15)<smiles>O=C(O)C(P)n1c(-c2ccccc2)nc2ccccc2c1=O</smiles>

\begin{tabular}{|c|c|c|c|}
\hline Compd & $\mathbf{R}$ & M.P., ${ }^{0} \mathrm{C}$ & Yield \% \\
\hline 1 & $-\mathrm{H}$ & $134-136$ & 58 \\
\hline 2 & $-\mathrm{CH}_{3}$ & $143-146$ & 79 \\
\hline 3 & $-\mathrm{CH}_{2}-\mathrm{CH}-\left(\mathrm{CH}_{3}\right)_{2}$ & $120-122$ & 70 \\
\hline 4 & - $\mathrm{CH}\left(\mathrm{CH}_{3}\right)-\mathrm{CH}_{2}-\mathrm{CH}_{3}$ & 190-193 & 93 \\
\hline 5 & $-\mathrm{CH}_{2}-\mathrm{SH}$ & $128-130$ & 78 \\
\hline 6 & $-\mathrm{CH}_{2}-\mathrm{S}-\mathrm{CH}_{3}$ & $240-244$ & 81 \\
\hline 7 & $\mathrm{H}_{2} \mathrm{OH}$ & 173-175 & 65 \\
\hline 8 & )-OH & $180-183$ & 53 \\
\hline 9 & $\overline{\mathrm{ONH}_{2}}$ & $130-132$ & 55 \\
\hline 10 & & $240-242$ & 57 \\
\hline 11 & $-\mathrm{Ph}(4-\mathrm{OH})$ & $240-242$ & 73 \\
\hline 12 & & $243-245$ & 71 \\
\hline 13 & $-\left(\mathrm{CH}_{2}\right)_{2}-\mathrm{COOH}$ & $230-232$ & 65 \\
\hline 14 & & $120-124$ & 61 \\
\hline 15 & & $130-132$ & 81 \\
\hline
\end{tabular}


IOSR Journal of Pharmacy

Vol. 2, Issue 1, Jan-Feb.2012, pp. 097-104

Table II: In vitro Antioxidant and Anti inflammatory activity of (B1-B15) by carrageenan induced rat paw edema assay

\begin{tabular}{|c|c|c|c|c|}
\hline Compound & $\begin{array}{l}\text { Edema volume } \\
\text { after } 3 \text { rd hr } \\
(\text { Mean } \pm \text { SEM) }\end{array}$ & $\begin{array}{c}\% \text { Edema } \\
\text { inhibition after } \\
\text { 3hours }\end{array}$ & $\begin{array}{l}\text { \% Reduction of } \\
\text { DPPH }(100 \mu \mathrm{M})\end{array}$ & $\begin{array}{c}\text { \%Nitric oxide scavenging } \\
(100 \mu \mathrm{M})\end{array}$ \\
\hline Control & $0.653 \pm 0.053^{\mathrm{a}}$ & - & - & - \\
\hline B1 & $0.296 \pm 0.008^{\mathrm{a}}$ & 45.2 & 35.6 & 31.2 \\
\hline B2 & $0.306 \pm 0.012^{\mathrm{a}}$ & 43.3 & 37.8 & 33.1 \\
\hline B3 & $0.270 \pm 0.020^{\mathrm{a}}$ & 49.2 & 39.6 & 32.9 \\
\hline B4 & $0.166 \pm 0.008^{a}$ & 51.6 & 42.2 & 385 \\
\hline B5 & $0.230 \pm 0.026^{\mathrm{a}}$ & 62.2 & 79 & 68.2 \\
\hline B6 & $0.266 \pm 0.008^{\mathrm{a}}$ & 57.7 & 62 & 61.6 \\
\hline B7 & $0.200 \pm 0.005^{\mathrm{a}}$ & 68.2 & 78.1 & 72.3 \\
\hline B8 & $0.160 \pm 0.026^{\mathrm{a}}$ & 69.8 & 76.2 & 74.7 \\
\hline B9 & $0.216 \pm 0.029^{a}$ & 60.3 & 46.8 & 42.8 \\
\hline B10 & $0.308 \pm 0.013^{\mathrm{a}}$ & 43.5 & 53.5 & 49.3 \\
\hline B11 & $0.232 \pm 0.026^{\mathrm{a}}$ & 62.1 & 82.4 & 79.1 \\
\hline B12 & $0.166 \pm 0.008^{a}$ & 51.6 & 63 & 52.4 \\
\hline B13 & $0.246 \pm 0.017^{\mathrm{a}}$ & 46.4 & 72 & 63.5 \\
\hline B14 & $0.273 \pm 0.014^{\mathrm{a}}$ & 49 & 61.2 & 59.7 \\
\hline B15 & $0.150 \pm 0.041^{\mathrm{a}}$ & 71.6 & 84.9 & 79.7 \\
\hline Standard & $\begin{array}{l}0.103 \pm 0.023^{\mathrm{a}} \\
\text { (Diclofenac } \\
\text { sodium) }\end{array}$ & 83.6 & $\begin{array}{c}85 \\
\text { (tocopherol) }\end{array}$ & $\begin{array}{c}81 \\
\text { (curcumin) }\end{array}$ \\
\hline
\end{tabular}

